\title{
ANÁLISE DISCRIMINANTE E RATINGS: UMA APLICACÃO DO MODELO Z" SCORE DE ALTMAN ÀS EMPRESAS DO SETOR AEROVIÁRIO BRASILEIRO, DE 2005 A 2010
}

\author{
DISCRIMINANT ANALYSIS AND RATINGS: AN APPLICATION OF ALTMAN'S "Z" SCORE MODEL TO \\ COMPANIES IN THE BRAZILIAN AIRLINE SECTOR FROM 2005 TO 2010 \\ ANÁLISIS DISCRIMINANTE Y RATINGS: UNA APLICACIÓN DEL MODELO Z" SCORE DE ALTMAN A \\ LAS EMPRESAS DEL SECTOR AÉREO BRASILEÑO DE 2005 A 2010
}

Rafael Sousa Ferreira

Especialista

Universidade Federal de Uberlândia rafaelferreiras@outlook.com

Carlos Roberto Souza Carmo

Mestre

Universidade Federal de Uberlândia carlosjj2004@hotmail.com

Vidigal Fernandes Martins

Mestre

Universidade Federal de Uberlândia vidigalfgv@gmail.com

Adeilson Barbosa Soares

Mestre

Universidade Federal de Uberlândia adeilsonbs@hotmail.com

Submetido em: 11/04/2013

Aprovado em: 02/07/2013

\section{RESUMO}

Com o objetivo de avaliar a eficácia do modelo Z" score de Altman (2002), esse estudo buscou avaliar empiricamente o desempenho econômico-financeiro das empresas do segmento aeroviário brasileiro, de 2005 a 2010, utilizando aquela técnica de análise discriminante e a tabela de ratings Standard \& Poor's. Além de ratificar a eficácia do modelo Z" score aplicado ao setor alvo desse estudo, entre outros resultados, essa investigação identificou que as empresas TAM e Gol apresentaram os melhores desempenhos dentre as empresas daquele segmento, o que permitiu sua recuperação econômico-financeira, em relação à crise econômica de 2008, já em 2009. Também foi observado que $60 \%$ das empresas analisadas alcançaram um rating médio CCC + , o que traduz uma vulnerabilidade a riscos de inadimplência, sendo que um terço das empresas integrantes da amostra de pesquisa apresentavam ratings superiores ao CCC+ antes da crise de 2008. Além disso, essa investigação constatou que as variáveis externas relacionadas àquela crise influenciaram significativamente, de forma negativa, os resultados econômico-financeiros de todas as empresas aéreas analisadas nessa investigação, o que contraria os resultados de alguns estudos anteriores que afirmaram que a situação econômica doméstica é mais impactante na situação econômico-financeira das empresas do segmento aeroviário brasileiro.

PALAVRAS-CHAVE: Risco. Modelagem. Falência. 


\begin{abstract}
Aiming to evaluate the effectiveness of the Altman's (2002) " $Z$ " score model, this study empirically assesses the financial performance of companies in the Brazilian airline sector from 2005 to 2010, using the technique of discriminant analysis and the Standard \& Poor's ratings table. In addition to ratifying the effectiveness of the " $Z$ " score model applied to the target sector of this study, this research identified, among other results, that the companies TAM and Gol showed the best performance among the companies in this sector, enabling their economic and financial recovery in 2009, following the 2008 economic crisis. It was also observed that $60 \%$ of the companies analyzed have achieved an average rating of CCC+, which reflects a vulnerability to default risks, given that a third of the companies in the survey sample had ratings higher than CCC + before the 2008 crisis. The research also found that external variables related to that crisis had a significant negative impact on the economic and financial results of all the airline companies analyzed in this study, contradicting the results of some previous studies, which report that the domestic economic situation has more impact on the economic and financial situation of companies in the Brazilian air transportation sector.
\end{abstract}

KEYWORDS: Risk. Modeling. Bankruptcy.

\title{
RESUMEN
}

Con el objetivo de valorar la eficacia del modelo Z" score de Altman (2002), este estudio intentó evaluar empíricamente el desempeño económico financiero de las empresas del segmento aéreo brasileño de 2005 a 2010, utilizando la técnica de análisis discriminante y la tabla de ratings Standard \& Poor's. Además de ratificar la eficacia del modelo $Z^{\prime \prime}$ score aplicado al sector de este estudio, esta investigación identificó, entre otros resultados, que las empresas TAM y Gol presentaron los mejores desempeños entre las empresas de dicho segmento, lo que permitió su recuperación económico financiera ya en 2009, en relación a la crisis económica de 2008. También se observó que el 60\% de las empresas analizadas alcanzaron un rating medio $\mathrm{CCC}+$, lo que traduce una vulnerabilidad a riesgos de insolvencia, considerando que un tercio de las empresas integrantes de la muestra de investigación presentaban ratings superiores al CCC+ antes de la crisis de 2008. Además, esta investigación constató que las variables externas relacionadas a la mencionada crisis influyeron significativamente, de forma negativa, sobre los resultados económico financieros de todas las empresas aéreas analizadas en esta investigación, lo que contradice los resultados de algunos estudios anteriores que afirmaban que la situación económica doméstica es más impactante en la situación económico financiera de las empresas del segmento aéreo brasileño.

PALABRAS CLAVE: Riesgo. Modelado. Quiebra.

\section{INTRODUÇÃO}

Apesar do seu notável crescimento ao longo dos últimos anos, o mercado aeroviário brasileiro apresenta problemas relacionados à ausência de infraestrutura, o que sinaliza uma considerável demanda por investimentos no setor (BNDES, 2012).

Dentre os obstáculos decorrentes daquele crescimento, além da necessidade de investimento em infraestrutura e das dificuldades para atender à demanda atual, o segmento aeroviário brasileiro tem que se preparar para uma demanda ainda maior, segundo as projeções realizadas até 2030 (BNDES, 2012).

Logo, a sobrevivência das empresas prestadoras de serviços de transporte aéreo é de fundamental importância para o atendimento das expectativas relacionadas à demanda, bem como para a 
economia brasileira. Pois, segundo dados da Agência Nacional de Aviação Civil (ANAC), o setor aeroviário brasileiro ocupa importante posição na geração da renda interna, uma vez que ele emprega milhares de pessoas e contribui fortemente para a receita pública nacional (ANAC, 2010).

Diante de tais evidências, destaca-se a considerável relevância desse tipo de atividade econômica como umas das justificativas para a escolha do mercado aeroviário brasileiro como segmento alvo desse estudo. Sendo que, para avaliar o desempenho econômico-financeiro das empresas desse mercado, optou-se pela utilização da técnica de análise discriminante múltipla proposta por Altman (2002), conhecida como score $Z^{\prime \prime}$.

A primeira versão da técnica de análise discriminante múltipla proposta por Altman (1968) foi o modelo Z, criado em 1968. Desde então, desenvolveram-se estudos relacionados que influenciaram fortemente na reformulação da modelagem analítica proposta por Altman (1968), até que, em 2002, Altman, com o objetivo de torná-lo aplicável ao mercado emergente, foi criou o modelo $Z^{\prime \prime}$ (ALTMAN, 2002).

Oportunamente, além de avaliar a sobrevivência das empresas prestadoras de serviços de transporte aéreo, no Brasil, com base em seu desempenho econômico-financeiro, vislumbra-se a possibilidade de se avaliar a aplicabilidade empírica do modelo $Z$ " de Altman (2002), como da técnica de análise discriminante múltipla desenvolvida para análise de empresas não fabricantes e pertencentes aos mercados considerados emergentes.

Nesse contexto, com o objetivo de avaliar a eficácia do modelo Z" score de Altman (2002), esse estudo buscou avaliar empiricamente o desempenho econômico-financeiro das empresas do mercado aeroviário brasileiro ao longo do período compreendido entre 2005 e 2010 , utilizando aquela técnica de análise discriminante e a tabela de ratings Standard \& Poor's. Para tanto, esta investigação foi conduzida a partir do seguinte questionamento direcionador: como a aplicação do modelo $Z^{\prime \prime}$ de Altman (2002) permite prever a possível descontinuidade das atividades operacionais das empresas do mercado aeroviário brasileiro, com base no seu desempenho econômico-financeiro?

Visando responder à problemática proposta para essa investigação, o presente trabalho foi dividido em outras quatro seções, além da presente introdução.

A seção dois foi destinada à fundamentação teórica dessa pesquisa. Nela, foi realizada uma breve contextualização acerca do mercado aeroviário brasileiro e sua situação em 2011; a seguir, foi abordada a temática relacionada aos ratings de crédito, à análise relacionada à evolução e à composição da modelagem de análise discriminante $Z$ escore de Altman, e, finalmente, os resultados de estudos correlatos a este.

Na seção três, foram abordados os procedimentos metodológicos para aplicação do modelo $Z^{\prime \prime}$ de Altman (2002) no mercado aeroviário brasileiro, bem como a descrição do processo de coleta e análise de dados.

A seção quatro foi destinada à análise dos dados financeiros das empresas, dos scores $Z^{\prime \prime}$ alcançados, os respectivos ratings e, consequentemente, à interpretação dos resultados.

Finalmente, na seção cinco, foram apresentadas as análises e as considerações finais acerca de todo o trabalho realizado, com especial atenção aos respectivos resultados e, ainda, sua comparação com os resultados de estudos realizados anteriormente.

\section{REFERENCIAL TEÓRICO}

Essa seção divide-se em quatro subseções, cujo objetivo foi constituir a plataforma teórica que suportou este estudo. A primeira delas apresenta uma breve contextualização acerca do mercado aeroviário brasileiro e sua situação em 2011, portanto, no primeiro ano após o período escolhido para realização dessa pesquisa, ou seja, 2005 a 2010. A segunda abordará a temática relacionada aos ratings de crédito. A terceira subseção foi destinada à análise relacionada à evolução e à composição da modelagem de análise discriminante Z score de Altman. A quarta e última seção foi destinada à abordagem dos resultados de estudos anteriores correlatos a este. 


\section{Mercado Aeroviário Brasileiro}

Impulsionado por fatores como crescimento da economia, a distribuição de renda e o aumento da concorrência, o mercado aeroviário brasileiro experimentou um notável crescimento na última década e viu a demanda pelo transporte aéreo doméstico de passageiros triplicar de 2002 a 2011 (ANAC, 2011).

Adicionalmente, no mesmo período, observou-se uma queda de cerca $43 \%$ no preço da tarifa aérea média doméstica, que variou de $R \$ 486,75$, em 2002, para $R \$ 276,25$, em 2011, já em valores reais de dezembro de 2011 (ANAC, 2011).

Com a liberdade tarifária, vigente desde 2001, e a liberdade de oferta, instituída em 2005, nos dias atuais, "[...] qualquer linha aérea pode ser operada por qualquer concessionária interessada - desde que observada a capacidade de infraestrutura aeroportuária e a prestação de serviço adequado $[\ldots]^{\prime \prime}$ (ANAC, 2011, p.7).

De 2010 para 2011, esse conjunto de fatores, entre outros, contribuiu consideravelmente para o crescimento de $16 \%$ na demanda por serviços de transporte aéreo doméstico e para um incremento de $13 \%$ na oferta desse tipo de serviço, o que culminou com uma taxa de aproveitamento das aeronaves brasileiras próxima de 70\% só em voos domésticos (ANAC, 2011).

Mas, a despeito de todos esses fatores positivos, a ANAC (2011) observa que fatores relacionados à elevação de preços do petróleo e às oscilações cambiais têm impactado negativamente os principais custos da aviação comercial brasileira, ou seja, o combustível, o arrendamento, o seguro e a manutenção das aeronaves. Uma vez que aquelas três categorias de custos somadas representaram mais de $47 \%$ dos custos e despesas totais das empresas do setor, em 2011, o setor apresentou um prejuízo líquido superior a $\mathrm{R} \$ 1,5$ bilhão.

Assim, todas essas particularidades constituem-se em relevantes justificativas para a escolha do mercado aeroviário brasileiro como segmento alvo desse estudo.

\section{Ratings de Crédito}

As avaliações de crédito realizadas pelas instituições financeiras são medidas conforme o risco da operação. A definição de ratings pela Standard \& Poor's (2003) é uma opinião corrente a respeito da capacidade financeira geral do emissor para saldar suas obrigações. Os ratings de emissores podem tanto ser corporativos, no caso de empresas emissoras, como soberanos, no caso de países.

$\mathrm{Na}$ atribuição dos ratings aos títulos, as instituições priorizam as características do emissor, as garantias, a qualidade da entidade que concedeu a garantia e a moeda na qual a emissão é denominada (SANVICENTE; MINARDI, 1998).

Sanvicente e Minardi (1998) destacam, entre outros, os seguintes pontos acerca do processo de atribuição de ratings: (i) um rating, ao se atribuído, leva em consideração informações atualizadas de caráter quantitativo e qualitativo; (ii) os ratings, normalmente, são alterados, retirados ou suspensos de acordo com a situação corrente e as informações disponíveis de um emissor de títulos de dívida; (iii) a capacidade de pagamento de um emissor de títulos de dívida é avaliada em moeda estrangeira, pois sua capacidade de pagamento em moeda corrente do seu país pode ser diferente.

Ao aliar as características do processo de emissão de ratings da Standard \& Poor's à sua metodologia Z" escore, Altman (2004) promoveu a fixação de uma matriz que correlacionasse essas duas metodologias, conforme detalhado no Quadro 1. Dentro desse contexto, deve-se mencionar a importância dessa matriz, pois, a partir do seu uso, é possível realizar uma interpretação mais eficaz dos scores. 
Quadro 1 - Equivalência $Z^{\prime \prime}$ score e rating Standard \& Poor's

\begin{tabular}{|c|c|}
\hline Rating S\&P Equivalente & Z" score Médio \\
\hline AAA & 8,15 \\
\hline $\mathrm{AA}+$ & 7,60 \\
\hline AA & 7,30 \\
\hline AA- & 7,00 \\
\hline$A+$ & 6,85 \\
\hline A & 6,65 \\
\hline A- & 6,40 \\
\hline $\mathrm{BBB}+$ & 6,25 \\
\hline BBB & 5,85 \\
\hline BBB- & 5,65 \\
\hline $\mathrm{BB}+$ & 5,25 \\
\hline $\mathrm{BB}$ & 4,95 \\
\hline BB- & 4,75 \\
\hline $\mathrm{B}+$ & 4,50 \\
\hline $\mathrm{B}$ & 4,15 \\
\hline B- & 3,75 \\
\hline $\mathrm{CCC}+$ & 3,20 \\
\hline $\mathrm{CCC}$ & 2,50 \\
\hline CCC- & 1,75 \\
\hline $\mathrm{D}$ & 0 \\
\hline
\end{tabular}

Fonte: Altman (2004, p. 3).

Altman (2004), ao determinar a matriz que correlacionou os scores com os ratings, revolucionou as técnicas de análises. Os cálculos realizados para obtenção dos scores passaram a ter um fundamento específico. Cada resultado possuía um rating e, assim, foi possível correlacionar um conceito teórico à real situação da empresa.

Os ratings Standard \& Poor's (2003) apresentados são de grande importância para realização desse estudo. A aplicação do modelo escore $Z$ " de Altman será atribuída à matriz, para assim determinar os respectivos ratings. Em linhas gerais, cada matriz obedece a uma classificação. Existem os ratings de grau de Investimento e os de grau Especulativo, conforme resumido no Quadro 2.

Conforme demonstrado no Quadro 2, os ratings possuem características específicas. São classificações que determinam a capacidade econômico-financeira de uma empresa. A Standard \& Poor's (1997) colocou em evidência os níveis de classificação de ratings, que vão de D a AAA. Uma empresa que alcança o rating $D$ está com sérios problemas financeiros, diferentemente das que atingem o rating AAA.

Quadro 2 - Ratings de créditos: Grau de Investimento e Especulação

\begin{tabular}{|l|l|}
\hline GRAU DE INVESTIMENTO \\
\hline AAA & $\begin{array}{l}\text { A maior qualidade de crédito. Capacidade de pagamento de juros e principal extremamente } \\
\text { elevada. }\end{array}$ \\
\hline AA+ & \multirow{2}{*}{ Capacidade muito forte de pagamento de juros e principal. } \\
\cline { 1 - 1 } AA & \\
\cline { 1 - 1 } AA- &
\end{tabular}




\begin{tabular}{|c|c|}
\hline A+ & \multirow{3}{*}{ Capacidade forte de pagar juros e principal. } \\
\hline A & \\
\hline A- & \\
\hline BBB+ & \multirow{3}{*}{ Capacidade adequada de pagar juros e principal. } \\
\hline BBB & \\
\hline BBB- & \\
\hline \multicolumn{2}{|c|}{ GRAU DE ESPECULAÇÃO } \\
\hline $\mathrm{BB}+$ & \multirow{3}{*}{ Provavelmente irá pagar juros e principais. Representa o menor grau de especulação. } \\
\hline BB & \\
\hline BB- & \\
\hline $\mathrm{B}+$ & \multirow{3}{*}{ Obrigações de alto risco. } \\
\hline B & \\
\hline B- & \\
\hline $\mathrm{CCC}+$ & \multirow{4}{*}{ Vulnerabilidade corrente a inadimplência. } \\
\hline CCC & \\
\hline CCC- & \\
\hline CC & \\
\hline C & Reservado a incomebonds quando não são pagos juros. \\
\hline D & Inadimplente. \\
\hline
\end{tabular}

Fonte: Adaptado de Standard \& Poor's (2003, p. 13).

No Brasil, várias empresas se utilizam desses ratings na avaliação dos seus resultados. Podemse citar as instituições financeiras, tais como: Banco BVA, Citibank, Bic Banco. Nesse sentido, vale ressaltar que os ratings Standard \& Poor's (1997) serão de grande valia na compreensão dos resultados alcançados nesse estudo.

\section{Z Score de Altman}

Relevantes acontecimentos no mercado financeiro vêm ocorrendo nos últimos anos. Grandes empresas estão se fortificando para suportar as turbulências do mercado. Para tanto, as análises das informações financeiras são importantes para a tomada de decisão.

A partir da análise discriminante múltipla é possível relacionar hipóteses qualitativas a um conjunto de informações quantitativas. A análise discriminante é muito utilizada na determinação de índices que preveem insolvências de empresas (BOUROCHE; SAPORTA, 1980). Este método estatístico constitui-se em uma importante ferramenta para tomada de decisão e, quando aplicada à análise de balanços, indica se uma empresa pertence à população de solventes ou à população de insolventes (MATARAZZO, 2007).

Silva (1997, p. 276) afirma que "na atividade empresarial, a análise discriminante veio sendo progressivamente utilizada na elaboração de modelos para a predição de empresas que poderão vir a se tornar inadimplentes com base em indicadores contábeis e financeiros".

Matarazzo (1998) comparou os modelos de previsão de falência com base em análises discriminantes. Os indicadores comparados possuem características distintas, no entanto foram aplicados no Brasil utilizando a análise discriminante múltipla. Os modelos comparados por Matarazzo (1998) foram propostos por Kanitz (1974), Altman (1968) e Elizabetsky (1976).

Kanitz (1974) realizou um estudo de previsão de falência no Brasil utilizando um modelo estatístico. A partir de 5 (cinco) índices extraídos dos demonstrativos financeiros, ele elaborou uma equação matemática utilizando técnica de regressão múltipla e análise discriminante. O objetivo do trabalho de Kanitz foi avaliar o risco de insolvência. O modelo proposto por Kanitz obteve um resultado de $80 \%$ (oitenta por cento) de eficácia quando aplicado nas empresas solventes e $68 \%$ (sessenta e oito por cento) nas empresas insolventes (MATARAZZO, 1998). 
Altman (1968) aplicou o modelo score Z em 66 (sessenta e seis) empresas americanas, sendo 33 (trinta e três) concordatárias e 33 não concordatárias, no período de 1946 a 1965. O modelo mostrou-se eficaz na classificação de $83 \%$ (oitenta e três por cento) das empresas solventes (MATARAZZO, 1998).

Elizabethsky (1976) desenvolveu um modelo matemático baseado na análise discriminante, cujo objetivo foi padronizar o processo de avaliação e a concessão de crédito a clientes. Utilizou-se uma amostra de 373 empresas industriais do setor de confecções, sendo 274 empresas classificadas como boas e 99 como ruins. O modelo de Elizabethsky atingiu uma margem de $74 \%$ (setenta e quatro por cento) de eficácia quando aplicado às empresas solventes (MATARAZZO, 1998).

A análise discriminante envolve a derivação de uma combinação linear de duas ou mais variáveis independentes que melhor discriminem os grupos predefinidos representados pela variável dependente. O critério para a definição dos pesos ou dos coeficientes da combinação linear é a maximização da variância entre os diferentes grupos em relação à variância dentro dos grupos (ALTMAN, 1968).

A análise discriminante múltipla busca compreender diferenças de grupo e predizer a probabilidade de uma entidade pertencer a um grupo, com base em diversas variáveis métricas; enquanto a análise discriminante simples tem um enfoque linear e produz resultados com base em critérios individuais e não de grupo (MATHIASI et al, 2011).

A previsão de insolvência por meio da análise discriminante múltipla tornou-se um assunto muito pesquisado a partir na década de 60 . Nesse período foram difundidas essas análises em diversas áreas, como: regressão logística, integração de sistemas de alarme, entre outras (MATHIASI HORTA et al., 2011).

Na década de 1960 foi desenvolvido por Altman (1968) um modelo para prever falências. O modelo, chamado de $Z$ escore, foi elaborado tendo como característica principal a aplicação do método da análise discriminante múltipla (Multivariate Discriminant Analysis - MDA). Esse método consiste na separação da amostra selecionada em grupos. Mediante a utilização do uso estatístico da MDA, determina-se um conjunto discriminante único de coeficientes que classifica cada observação individual em um dos grupos. O modelo desenvolvido por Altman (1968) está detalhado na Fórmula 1.

\section{$Z=0,012 \times 1+0,014 \times 2+0,033 \times 3+0,006 \times 4+0,999 \times 5$}

Sendo que: $\mathrm{X} 1$ = (ativo circulante - passivo circulante) / total de ativos; $\mathrm{X} 2=$ lucros acumulados / total de ativos; $\mathrm{X} 3=$ resultado antes das despesas financeiras e impostos [EBIT] / total de ativos; $\mathrm{X} 4=$ valor de mercado do patrimônio / valor contábil do total de débitos; X5 = vendas / total de ativos.

A variável X1 está presente na função, pois é capaz de medir o ativo líquido da empresa, a curto prazo, ou, ainda, o seu capital de giro, comparativamente ao respectivo ativo total (ALTMAN, 1968). A variável X2 determina quanto do ativo total da entidade já foi armazenado sob a forma de lucros, ou, ainda, quanto dos lucros foi reinvestindo na manutenção dos ativos necessários ao giro do negócio (ALTMAN, 1968). A variável X3 mede o retorno operacional gerado pelos ativos da empresa (ALTMAN, 1968). O fator X4 tem o objetivo de apontar qual a proporção entre o valor de mercado do patrimônio da entidade em relação aos respectivos débitos (ALTMAN, 1968). E, por fim, a variável X5 é uma medida de capacidade da gestão em girar os seus ativos em função das vendas (ALTMAN, 1968).

Altman (1968) aplicou empiricamente o modelo em 66 (sessenta e seis) empresas americanas, sendo 33 (trinta e três) concordatárias e 33 não concordatárias, no período de 1946 a 1965. Todas as variáveis, com exceção de X5, apresentaram uma "estatística f" satisfatória ao nível de significância de $1 \%$. No entanto, quando se verificou a contribuição relativa de cada variável ao poder discriminante da função, verificou-se que X3 foi a variável mais importante, seguida por X5. O modelo mostrou-se eficaz na classificação de $95 \%$ (noventa e cinco por cento) das empresas um ano antes do evento da concordata (ALTMAN, 1968).

Posteriormente, em uma nova modelagem, Altman, Baidya e Dias (1979) propuseram uma nova equação, conforme descrito na Fórmula 2. 
Altman, Baidya e Dias (1979) aplicaram o modelo reformulado em 1979 no Brasil. Foi selecionada uma amostra de 23 empresas concordatárias ou liquidadas. A variável X4 do modelo original de Altman foi modificada no intuito de adaptar ao contexto brasileiro. Houve a substituição do valor de mercado do patrimônio líquido pelo valor contábil do patrimônio líquido. A variável X4 passou a ser composta pela divisão do patrimônio líquido pelo exigível total, sendo que os pesquisadores destacaram que a razão daquele modelo inicial se deve ao fato do modelo $Z$ escore ser indicado ao setor público e, portanto, para atender ao setor privado, seria necessária essa adequação (ALTMAN, 2002). Cabe ressaltar que os resultados alcançados pela aplicação do modelo revisado em 1979 foram satisfatórios. Em termos de confiabilidade dos resultados da aplicação do modelo $Z^{\prime}$ score de Altman (1979), as classificações em empresas falidas foram feitas com $91 \%$ de acertos e as classificações das empresas saudáveis foram feitas com 97\% de exatidão (ALTMAN, 2002).

No decorrer dos anos, vários testes foram realizados em empresas e, com isso, as equações do modelo $Z$ score foram sendo alteradas conforme as necessidades. A última versão do modelo $Z$ score foi proposta por Altman em 2002. Com o objetivo de torná-lo praticável diante das demandas da sociedade, Altman (2002) alterou algumas variáveis na função. A proposta desse novo modelo revisado era de aprimorar a análise interna de risco de crédito.

A revisão realizada por Altman (2002) foi uma adaptação à realidade das empresas não fabricantes e pertencentes a mercados considerados emergentes. Teve como aspecto principal a evidenciação da capacidade financeira das empresas não localizadas nos Estados Unidos. Dentro desse contexto, as alterações consistiram em extrair a variável X5 e informar na variável X4 o valor contábil do patrimônio liquido e, ainda, adicionou um termo constante de $+3,25$ que influenciava diretamente na situação de inadimplência das empresas avalias, conforme demonstrado na Fórmula 3.

$$
Z^{\prime \prime}=6,56 \times 1+3,26 \times 2+6,72 \times 3+1,05 \times 4+3,25
$$

A inserção da constante 3,25 na função ocorreu com o propósito de padronizar o escore alcançado quando as variáveis $X$ apresentassem valor igual a 0 (zero). Altman (2002, p. 22, tradução nossa) esclarece que "no mercado emergente, o modelo foi acrescido de uma constante de 3,25, de modo a padronizar as avaliações com uma pontuação de zero $(0)[\ldots]$ ". Importante ressaltar que o objetivo maior era adaptar o modelo à realidade dos países emergentes e, dentro desse contexto, a variável X5 não poderia permanecer, pois o modelo deveria minimizar o efeito potencial da indústria e destacar o giro do ativo (ALTMAN, 2002).

Diante das revisões realizadas na função score $Z$ de Altman, ela tornou-se bastante utilizada no cenário mundial. Alguns pesquisadores, tais como Sanvicente e Minardi (1998) e Silva (1997), relatam que no Brasil não existem muitas aplicações dessa função, no entanto há pesquisas que sustentam a credibilidade do escore $Z^{\prime \prime}$ de Altman (MATHIASI et al., 2011).

\section{Estudos Anteriores Relacionados à Análise de Insolvência de Empresas Aéreas Brasileiras}

Com o objetivo de avaliar a possibilidade de insolvência nas principais empresas de aviação do mercado brasileiro, Aranha e Lins Filho (2005) aplicaram o modelo de previsão de falência de Kanitz nas demonstrações financeiras da Varig, Vasp, TAM e Gol no período de 2002 a 2004.

Mediante a realização da análise quantitativa daquelas demonstrações contábeis, além de constatarem a aplicabilidade empírica do modelo de Kanitz, Aranha e Lins Filho (2005) identificaram problemas relacionados à situação financeira da Varig e da Vasp e aspectos positivos relacionados à situação econômico-financeira da TAM e da Gol.

A partir da análise das demonstrações financeiras das principais companhias aéreas brasileiras (Transbrasil, Varig, Vasp, TAM e Gol), ao longo do período compreendido 1995 a 2005, Antunes, 
Alves e Antunes (2007) avaliaram a possibilidade dos Stakeholders daquelas empresas extraírem informações suficientes que Ihes possibilitassem prever a descontinuidade daquelas empresas e/ ou o seu sucesso.

Os resultados da pesquisa de Antunes, Alves e Antunes (2007), entre outros fatores, evidenciaram que, apesar do parecer dos auditores independentes apresentar observações relativas à continuidade das suas atividades operacionais, a Transbrasil e a Varig apresentaram índices de solvência e lucratividade em declínio no período analisado. Eles observaram também que a Vasp realizou duas reavaliações no ativo imobilizado, o que impediu que o seu patrimônio líquido apresentasse uma situação líquida negativa. Diferentemente das demais, a TAM e a Gol, além de demonstrarem uma preocupação com a transparência na divulgação de suas demonstrações financeiras, evidenciaram resultados positivos, bem como um aumento na sua participação no mercado aeroviário brasileiro.

Oliveira, Scarpel e Oliveira (2008) realizaram um estudo com o objetivo de identificar os determinantes da situação de insolvência das principais companhias aéreas do período regulatório no Brasil. Para tanto, os autores compararam os casos das situações falimentares da Varig, Vasp e Transbrasil, no período 1983-2003, com a evolução do segmento aeroviário brasileiro como um todo.

A partir de um estudo econométrico acerca dos determinantes da situação de insolvência daquelas três empresas, Oliveira, Scarpel e Oliveira (2008) observaram que seria possível antecipar os problemas que levaram à saída daquelas companhias aéreas do mercado nacional. Adicionalmente, foi observado que a situação da economia doméstica é mais impactante para as empresas deste segmento econômico, do que as oscilações cambiais em si, apesar de vários custos das empresas aéreas serem avaliados em dólares e fortemente influenciados pelo câmbio.

A partir de uma amostra formada pelas empresas TAM Linhas Aéreas S/A e Gol Linhas Aéreas Inteligentes S/A, escolhidas pela acessibilidade das informações, Nascimento, Pereira e Hoeltgebaum (2010) analisaram a aplicação de modelos de previsão de insolvências no período de 2004 a 2008.

Com a aplicação das modelagens de Elizabetsky (1976) e Altman, Baidya e Dias (1979), entre outros, Nascimento, Pereira e Hoeltgebaum (2010) concluíram que a Gol apresentou um desempenho superior ao da TAM, que não se apresentou uniforme ao longo dos cinco anos analisados.

Villa e Espejo (2011) buscaram avaliar a situação econômico-financeira das duas maiores empresas de transporte aéreo brasileiro (TAM e Gol), nos anos de 2007 a 2009, com vistas às necessidades de adequação geradas a partir de uma das suas das maiores demandas turísticas emergentes no cenário nacional: a Copa do Mundo de 2014.

Segundo Villa e Espejo (2011), a análise realizada a partir do modelo indicado por Fleuriet demonstrou uma situação divergente entre elas, sendo que a Gol apresentou-se a mais estável financeiramente nestes anos. $O$ estudo também indicou que ambas precisam buscar mecanismos de proteção contra possíveis crises econômicas mundiais, como aquela ocorrida no ano de 2008. Além dessas e de outras evidências, foi contatado que as duas empresas encontram-se em uma situação financeira confortável, pois ambas obtiveram uma recuperação de resultados em 2009.

\section{METODOLOGIA}

Para atingir o objetivo proposto para essa investigação, inicialmente se buscou compreender a teoria relacionada à análise discriminante com base no modelo Z" de Altman (2002). Para tanto, foi realizado um estudo sobre as pesquisas desenvolvidas por Altman (2002) desde a criação da função baseada na técnica de análise descriminante múltipla, o modelo $Z$ de Altman (1968), entre outros estudiosos, como Elizabetsky (1976), Kanitz (1974), Sanvicente e Minardi (1998). Adicionalmente, foram estudados os aspectos relativos aos ratings de crédito e, ainda, foram avaliados os principais resultados de estudos correlatos a este.

A partir do embasamento teórico, iniciou-se um estudo para determinar o segmento econômico para aplicação do modelo $Z$ ". Nesse momento, foram ponderadas as particularidades que o modelo $Z^{\prime \prime}$ necessita para ser aplicável e, com base nisso, determinou-se que a pesquisa seria desenvolvida a partir de um estudo de caso múltiplo no segmento aeroviário brasileiro. 
Ressaltando os benefícios de se realizar estudo de caso, Yin (2005, p. 19) observa que "os estudos de casos representam a estratégia mais indicada quando o pesquisador tem pouco controle ou nenhum controle sobre os acontecimentos estudados e quando o foco se encontra em fenômenos inseridos em contexto da vida real" e, ainda, uma vez bem fundamentada determinada teoria, "os estudos de casos servem confirmar, contestar e, até mesmo, estender tal teoria" (YIN, 2005, p. 62).

A modelagem $Z$ " desenvolvida por Altman (2002) está baseada na análise discriminante múltipla. Desta forma, ao aliar aquela metodologia ao processo de atribuição de ratings, foi possível explorar informações quantitativas para obter análises de resultados de natureza qualitativa. Nesse sentido, o fato de utilizar-se dos dados fornecidos pelos demonstrativos financeiros para obter resultados sobre a capacidade financeira da entidade é característica deste tipo de análise. Nesse contexto, o estudo aplicou o modelo Z" de Altman (2002) mediante as informações contidas nos demonstrativos financeiros das empresas do segmento aeroviário nos anos de 2005 a 2010, conforme informações resumidas no Quadro 3. A razão do período analisado está pautada nos eventos ocorridos nesses anos, como crise financeira, fusões e aquisições de grandes empresas.

Quadro 3 - Empresas do segmento aeroviário brasileiro

\begin{tabular}{|l|l|}
\hline RAZÃo SOCIAL & DENOMINAÇÃo \\
\hline Abaeté Linhas Aéreas S/A & Abaeté \\
\hline Absa Cargo Airline S/A & Absa \\
\hline Cruiser Linhas Aéreas Ltda. & Cruiser \\
\hline Gol Linhas Aéreas S/A & Gol \\
\hline Mega Linhas Aéreas Ltda. & Mega \\
\hline NHT Linhas Aéreas Ltda. & NHT \\
\hline Oceanair Linhas Aéreas Ltda. & Oceanair \\
\hline Pantanal Linhas Aéreas S/A & Pantanal \\
\hline Passaredo Linhas Aéreas Ltda. & Passaredo \\
\hline Puma Air Linhas Aéreas Ltda. & Puma \\
\hline TAM Linhas Aéreas S/A & TAM \\
\hline Total Line Linhas Aéreas Ltda. & Total \\
\hline Trip Linhas Aéreas S/A & Trip \\
\hline Variglog Cargo S/A & Variglog \\
\hline Webjet Linhas Aéreas S/A & Webjet \\
\hline
\end{tabular}

Fonte: Adaptado de ANAC (2010, p. 96).

Com relação às fontes de dados, observa-se que as referidas demonstrações financeiras foram disponibilizadas no ambiente virtual da Agência Nacional de Aviação Civil (ANAC). Com relação ao tratamento dos dados coletados, destaca-se que foi realizada a atualização dos valores contidos naqueles demonstrativos para moeda de poder aquisitivo de uma mesma data, no caso, 31/12/2012. Para tanto, o Índice de Preço ao Consumidor Amplo (IPCA) se mostrou ideal para o tipo de mercado analisado, pois mede a variação nos preços de produtos e serviços consumidos pelas famílias com rendas entre 1 e 40 salários mínimos, sendo esse o perfil do principal consumidor desse tipo de serviço.

Com base nas demonstrações financeiras das empresas alvo desse estudo, foram realizados os cálculos para determinar os scores de cada empresa, em cada exercício social, segundo do modelo $Z^{\prime \prime}$ de Altman (2002). Esses scores foram comparados à matriz Standard \& Poor's (2003), com o objetivo de aprimorar a sua interpretação. Os ratings expressos na matriz Standard \& Poor's remetem, individualmente, às interpretações econômicas e financeiras. Cabe observar que a matriz utilizada nesse trabalho refere-se à matriz de ratings de grau de investimento e grau especulativo, extraída do site da Standard \& Poor's, conforme já resumido e demonstrado anteriormente no Quadro 2, localizado na seção 2.2 deste artigo. 
Diante do exposto, esse estudo é classificado, quanto aos seus objetivos, como uma pesquisa exploratória. Em relação à abordagem do problema, trata-se de uma pesquisa qualitativa. E quanto aos procedimentos técnicos de coleta e análise de dados, a pesquisa foi realizada sob a forma de estudo de caso múltiplo.

\section{ANÁLISE DOS DADOS E APRESENTAÇÃO DOS RESULTADOS}

O modelo Z" score de Altman (2002) possui 5 (cinco) variáveis que são multiplicadas com seus respectivos coeficientes, os valores encontrados são somados e desta forma é determinado o score $Z^{\prime \prime}$. O modelo é caracterizado pela função $Z^{\prime \prime}=6,56 \times 1+3,26 \times 2+6,72 \times 3+1,05 \times 4+3,25$. Com base nos dados contidos nos demonstrativos das empresas analisadas, as Tabelas 1 a 4 demonstram os resultados dos respectivos coeficientes.

Tabela 1 - Resultado da variável X1

\begin{tabular}{lllllll}
\hline X1: (ativo circulante - passivo circulante) / total de ativos \\
\hline Empresas & 2005 & 2006 & 2007 & $\mathbf{2 0 0 8}$ & $\mathbf{2 0 0 9}$ & $\mathbf{2 0 1 0}$ \\
\hline Abaeté & 0,2273 & 0,2659 & 0,1940 & 0,1171 & 0,4033 & 0,4804 \\
Absa & 0,1314 & 0,1718 & 0,0164 & 0,0200 & $-0,0544$ & 0,4439 \\
Cruiser & $-0,7253$ & $-0,7464$ & $-0,3595$ & $-1,0113$ & $-0,0010$ & $-1,2303$ \\
Gol & 0,2522 & 0,1992 & 0,0591 & $-0,0652$ & 0,0279 & 0,1040 \\
Mega & $-0,0315$ & $-0,1179$ & 0,1377 & 0,0321 & 0,7810 & $-0,1070$ \\
NHT & $-1,3641$ & 0,3428 & $-0,1238$ & $-0,0193$ & 0,0018 & $-0,0152$ \\
Oceanair & $-1,3569$ & $-0,1801$ & $-0,1461$ & $-0,1116$ & $-0,3313$ & $-0,3273$ \\
Pantanal & $-0,3378$ & $-0,1739$ & $-0,3311$ & $-0,5495$ & $-1,0551$ & $-0,1373$ \\
Passaredo & $-0,0184$ & $-0,0682$ & 0,0096 & $-0,0798$ & $-0,2479$ & $-0,1977$ \\
Puma & $-0,3664$ & 0,1251 & $-1,0306$ & $-1,7755$ & $-1,6475$ & $-2,5615$ \\
TAM & 0,1360 & 0,2818 & 0,2942 & $-0,0546$ & $-0,0911$ & $-0,1140$ \\
Total & $-0,2038$ & $-0,2528$ & $-0,1896$ & $-0,1427$ & $-0,1317$ & $-0,0862$ \\
Trip & $-0,8434$ & 0,2815 & 0,3946 & 0,0340 & $-0,0644$ & $-0,0068$ \\
Variglog & 0,0209 & $-0,0108$ & 0,1546 & $-0,2549$ & $-0,3601$ & $-0,4981$ \\
Webjet & $-0,9363$ & $-0,9362$ & $-0,7555$ & $-0,1870$ & $-0,4355$ & $-0,0379$ \\
\hline Fon
\end{tabular}

Fonte: Elaborada pelos autores com base nos dados da pesquisa.

A variável X1 é caracterizada por mensurar a participação relativa do ativo líquido da empresa no seu ativo total. O capital de giro é definido como a diferença entre ativo e passivo circulante, portanto, é correto afirmar que o ativo líquido é a representatividade do capital de giro sobre o ativo total (MATARAZZO, 2007). Dentro desse contexto, a referida variável tem função importante no modelo e, quanto maior o índice, melhor é a situação financeira da empresa. Ao realizar os cálculos iniciais, foi possível perceber que algumas empresas alcançaram um resultado inferior a 0 (zero). As empresas inoperantes atualmente (Cruiser, Puma e Variglog) apresentaram um resultado inferior a 0 (zero) no decorrer dos anos, portanto, um capital de giro negativo.

Tabela 2 - Resultado da variável X2

\begin{tabular}{lllllll}
\hline X2: lucros acumulados / total de ativos \\
\hline Empresas & $\mathbf{2 0 0 5}$ & $\mathbf{2 0 0 6}$ & $\mathbf{2 0 0 7}$ & $\mathbf{2 0 0 8}$ & $\mathbf{2 0 0 9}$ & $\mathbf{2 0 1 0}$ \\
\hline Abaeté & $-0,4541$ & $-0,2314$ & $-0,4504$ & $-0,5222$ & $-0,1794$ & $-0,0190$ \\
Absa & $-0,0728$ & $-0,0300$ & $-0,0191$ & 0,0043 & $-0,0215$ & $-0,0003$
\end{tabular}




\begin{tabular}{lcccccc} 
Cruiser & 0,0216 & $-0,0336$ & $-0,0386$ & $-0,4074$ & $-0,0004$ & $-1,3093$ \\
Gol & 0,0999 & 0,0906 & 0,0804 & $-0,2244$ & 0,0490 & 0,0525 \\
Mega & $-0,1301$ & $-0,1323$ & $-0,1482$ & $-0,8006$ & 1,4686 & $-0,3617$ \\
NHT & $-8,0914$ & $-0,5571$ & $-1,1412$ & $-1,0299$ & $-0,9639$ & $-2,6897$ \\
Oceanair & $-6,3639$ & $-2,6572$ & $-2,0603$ & $-1,7413$ & $-4,8130$ & $-2,7852$ \\
Pantanal & $-0,2700$ & $-0,0478$ & $-0,2480$ & $-0,5524$ & $-3,0834$ & $-1,7496$ \\
Passaredo & $-0,7539$ & $-0,6556$ & $-0,5474$ & $-0,3753$ & $-0,2847$ & $-0,0844$ \\
Puma & $-2,1228$ & 0,0680 & $-3,1809$ & $-4,2421$ & $-3,9867$ & $-5,8921$ \\
TAM & 0,0823 & 0,2807 & 0,1360 & $-0,0124$ & 0,0751 & 0,0912 \\
Total & 0,0090 & 0,0155 & 0,0133 & 0,0253 & 0,1850 & 0,1577 \\
Trip & $-0,5582$ & 0,1762 & 0,3918 & $-0,0587$ & 0,0425 & 0,0765 \\
Variglog & $-0,9036$ & $-0,6174$ & $-0,9868$ & $-0,4016$ & $-0,3625$ & $-0,5286$ \\
Webjet & $-1,8253$ & $-1,8250$ & $-0,7376$ & $-0,1738$ & $-0,6950$ & $-0,3910$ \\
\hline
\end{tabular}

Fonte: Elaborada pelos autores com base nos dados da pesquisa.

Mediante a análise da variável $\mathrm{X} 2$ pode-se determinar o retorno alcançado e acumulado em relação ao ativo da empresa. Conforme pode ser observado na Tabela 2, a maioria das empresas do setor apresentou prejuízo no decorrer dos anos. Sendo que, em uma análise realizada diretamente nos respectivos demonstrativos, constatou-se que, dentre as empresas inoperantes (Cruiser, Variglog e Puma), o prejuízo no decorrer dos anos foi superior ao próprio ativo. Com base nisso, pode-se determinar que a variável analisada influenciou fortemente o resultado dos scores alcançados.

Tabela 3 - Resultado da variável X3

X3: resultado antes das despesas financeiras e impostos (EBIT) / total de ativos

\begin{tabular}{lllllll}
\hline Empresas & $\mathbf{2 0 0 5}$ & $\mathbf{2 0 0 6}$ & $\mathbf{2 0 0 7}$ & $\mathbf{2 0 0 8}$ & $\mathbf{2 0 0 9}$ & $\mathbf{2 0 1 0}$ \\
\hline Abaeté & $-0,0687$ & 0,0564 & $-0,1169$ & $-0,0250$ & 0,3433 & 0,1591 \\
Absa & $-0,0598$ & 0,0394 & 0,0228 & 0,0313 & $-0,1224$ & $-0,0035$ \\
Cruiser & 0,0436 & $-0,0303$ & 0,0333 & $-0,1692$ & $-0,0254$ & $-0,1341$ \\
Gol & 0,3217 & 0,3093 & 0,1251 & $-0,2558$ & 0,0540 & 0,0887 \\
Mega & $-0,0607$ & 0,0288 & 0,0263 & $-0,0656$ & 0,0368 & 0,1858 \\
NHT & 0,0040 & $-0,5965$ & $-0,7639$ & $-0,2477$ & $-0,1349$ & $-0,4938$ \\
Oceanair & $-1,6818$ & $-1,2064$ & $-0,8994$ & $-1,2678$ & $-0,5514$ & $-0,2214$ \\
Pantanal & 0,0834 & 0,0458 & $-0,1168$ & $-0,1802$ & $-1,8791$ & 0,0632 \\
Passaredo & 0,0198 & $-0,0354$ & 0,0098 & $-0,0375$ & 0,0588 & $-0,0308$ \\
Puma & $-0,1613$ & 0,1613 & $-0,2374$ & $-0,4597$ & 0,8070 & 1,6128 \\
TAM & 0,1438 & 0,1989 & 0,1261 & 0,0553 & 0,0318 & 0,0659 \\
Total & 0,1405 & 0,1632 & 0,1345 & 0,0660 & 0,0311 & 0,1255 \\
Trip & 0,1568 & $-0,0108$ & 0,0138 & $-0,0041$ & 0,0200 & 0,0718 \\
Variglog & 0,1406 & $-0,1237$ & $-0,5574$ & $-0,1680$ & $-0,1759$ & $-0,0995$ \\
Webjet & $-1,7664$ & $-1,7603$ & $-0,5220$ & $-0,3166$ & $-0,2823$ & 0,0993 \\
\hline Fonte: Elabo & 0,0503 & & & \\
\hline
\end{tabular}

Fonte: Elaborada pelos autores com base nos dados da pesquisa. 
A variável X3 mensura a rentabilidade operacional dos ativos da empresa antes das despesas financeiras e dos impostos. A variável analisada não influenciou significativamente o score $Z^{\prime \prime}$ de Altman (2002) alcançado pelas empresas do setor. Diferentemente das anteriores, nessa análise observou-se que a maioria das empresas em operação caracterizou-se por manter o resultado operacional superior a 0 (zero). No entanto, as empresas inoperantes (Variglog, Cruiser e Puma) alcançaram um score abaixo de 0 (zero), contrapondo a maioria das empresas do segmento, conforme informações resumidas na Tabela 3.

Tabela 4 - Resultado da variável X4

X4: patrimônio líquido / exigível total

\begin{tabular}{|c|c|c|c|c|c|c|}
\hline Empresas & 2005 & 2006 & 2007 & 2008 & 2009 & 2010 \\
\hline Abaeté & 0,3680 & 0,5178 & 0,2899 & 0,1750 & 0,7199 & 0,9744 \\
\hline Absa & $-0,0470$ & 0,0088 & 0,0367 & 0,0492 & 0,0254 & 0,0496 \\
\hline Cruiser & 0,0782 & 0,0165 & 0,0588 & $-0,2324$ & $-0,2325$ & $-0,5338$ \\
\hline Gol & 0,7551 & 0,5733 & 0,4323 & 0,3166 & 0,5794 & 0,5075 \\
\hline Mega & 0,0736 & 0,0591 & 0,2472 & 0,0163 & 0,0000 & 0,2493 \\
\hline NHT & $-0,8740$ & 0,0326 & 0,1137 & 0,2388 & 0,0053 & 0,4542 \\
\hline Oceanair & $-0,8596$ & $-0,1454$ & 0,0363 & 0,0970 & 0,0103 & $-0,1986$ \\
\hline Pantanal & $-0,0185$ & 0,2491 & 0,0150 & $-0,2132$ & $-0,7141$ & $-0,5851$ \\
\hline Passaredo & 1,7166 & 0,8326 & 0,4786 & 0,1805 & 0,2443 & 0,1197 \\
\hline Puma & $-0,4802$ & 1,0224 & $-0,6463$ & $-0,7351$ & $-0,6700$ & $-0,8102$ \\
\hline TAM & 0,1433 & 0,4470 & 0,3292 & 0,0496 & 0,1623 & 0,1795 \\
\hline Total & 0,0772 & 0,0729 & 0,0507 & 0,0618 & 0,2794 & 0,2691 \\
\hline Trip & $-0,2739$ & 0,4994 & 0,9107 & 0,1405 & 0,1784 & 0,2113 \\
\hline Variglog & 0,0663 & $-0,1227$ & $-0,3606$ & 0,0328 & 0,0824 & $-0,0585$ \\
\hline Webjet & $-0,5413$ & $-0,5412$ & $-0,1811$ & 0,1953 & $-0,2894$ & 0,0320 \\
\hline
\end{tabular}

Fonte: Elaborada pelos autores com base nos dados da pesquisa.

A variável X4 avalia quanto do ativo da empresa é financiado pelo capital próprio (Patrimônio Líquido). Desta forma, essa variável aponta a independência do capital de terceiros da empresa, pois quanto maior o coeficiente, menor a dependência por capital de terceiros. Algumas empresas do segmento apresentaram, no decorrer do período analisado, resultados inferiores a 0 (zero), conforme demonstrado na Tabela 4. A justificativa para tais resultados está pautada no prejuízo das empresas, que influenciou negativamente o Patrimônio Líquido e consequentemente a variável X4.

A variável X5 mensura a capacidade da gestão em lidar com condições competitivas, relacionando as vendas com a geração de ativos (ALTMAN, 2002). Conforme já explicado, Altman (2002), em seu modelo $Z^{\prime \prime}$, fixou a constante 3,25 , visando adequar a função à realidade dos mercados emergentes.

Depois de realizadas as interpretações e as análises de cada variável e, ainda, obtidos os respectivos scores, procedeu-se à sua análise interpretativa de acordo com a matriz de ratings proposta pela Standard \& Poor's (2003). Assim, as Tabelas 5 a 10 demonstram os resultados alcançados com a aplicação do modelo Z" de Altman (2002) durante os anos de 2005 a 2010, respectivamente. 
Tabela 5 - Apresentação do score Z" e atribuição de rating em 2005

\begin{tabular}{|c|c|c|c|c|c|c|c|}
\hline $\begin{array}{l}\text { Coeficiente } \\
\text { Empresas }\end{array}$ & $\begin{array}{l}6,56 \\
\mathbf{X 1}\end{array}$ & $\begin{array}{l}3,26 \\
\mathbf{x} 2\end{array}$ & $\begin{array}{l}6,72 \\
x 3\end{array}$ & $\begin{array}{l}1,05 \\
\times 4\end{array}$ & $\begin{array}{l}3,25 \\
\times 5\end{array}$ & $\begin{array}{l}\text { Score } \\
\text { Z" }\end{array}$ & $\begin{array}{l}\text { Rating } \\
\text { S\&P }\end{array}$ \\
\hline Gol & 0,2522 & 0,0999 & 0,3217 & 0,7551 & 3,25 & 8,1849 & AAA \\
\hline TAM & 0,1360 & 0,0823 & 0,1438 & 0,1433 & 3,25 & 5,5271 & $\mathrm{BB}+$ \\
\hline Absa & 0,1314 & $-0,0728$ & $-0,0598$ & $-0,0470$ & 3,25 & 3,4235 & $\mathrm{CCC}+$ \\
\hline Abaeté & 0,2273 & $-0,4541$ & $-0,0687$ & 0,3680 & 3,25 & 3,1853 & $\mathrm{CCC}$ \\
\hline Passaredo & $-0,0184$ & $-0,7539$ & 0,0198 & 1,7166 & 3,25 & 2,6074 & $\mathrm{CCC}$ \\
\hline Total & $-0,2038$ & 0,0090 & 0,1405 & 0,0772 & 3,25 & 2,9674 & $\mathrm{CCC}$ \\
\hline Mega & $-0,0315$ & $-0,1301$ & $-0,0607$ & 0,0736 & 3,25 & 2,2891 & CCC- \\
\hline Cruiser & $-0,7253$ & 0,0216 & 0,0436 & 0,0782 & 3,25 & $-1,0629$ & D \\
\hline NHT & $-1,3641$ & $-8,0914$ & 0,0040 & $-0,8740$ & 3,25 & $-32,966$ & D \\
\hline Oceanair & $-1,3569$ & $-6,3639$ & $-1,6818$ & $-0,8596$ & 3,25 & $-38,601$ & D \\
\hline Pantanal & $-0,3378$ & $-0,2700$ & 0,0834 & $-0,0185$ & 3,25 & 0,6950 & D \\
\hline Puma & $-0,3664$ & $-2,1228$ & $-0,1613$ & $-0,4802$ & 3,25 & $-7,6623$ & D \\
\hline Trip & $-0,8434$ & $-0,5582$ & 0,1568 & $-0,2739$ & 3,25 & $-3,3366$ & D \\
\hline Variglog & 0,0209 & $-0,9036$ & 0,1406 & 0,0663 & 3,25 & 1,4554 & D \\
\hline Webjet & $-0,9363$ & $-1,8253$ & $-1,7664$ & $-0,5413$ & 3,25 & $-21,281$ & D \\
\hline
\end{tabular}

Fonte: Elaborada pelos autores com base nos dados da pesquisa.

Os scores Z" alcançados em 2005 pelas empresas do segmento aeroviário tiveram como característica a disparidade. Esta afirmativa pode ser constatada quando observados os resultados divergentes entre as empresas, conforme demonstra a Tabela 5. No ano analisado, é possível perceber a superioridade das empresas Gol e TAM. Importante ressaltar que as organizações citadas são as principais geradoras de receitas do setor (ANAC, 2005). As referidas empresas obtiveram rating $\mathrm{AAA}$ e $\mathrm{BB}+$, respectivamente.

Deve ser observado que, em 2005, as empresas inoperantes atualmente (Cruiser, Puma e Variglog) apresentaram um score inferior às demais empresas, com rating D. Nesse momento, destacam-se as tendências das referidas empresas à inoperância. Contudo, observa-se que além daquelas empresas, a NHT, a Oceanair, a Pantanal, a Trip e a Webjet alcançaram rating que tendem a descontinuação das atividades.

Semelhante ao acontecido em 2005, em 2006, as empresas Gol e TAM foram superiores em relação às demais, alcançado um rating $A A+$ e $A A$, respectivamente, conforme informações resumidas na Tabela 6. A particularidade foi a inversão de posições, sendo que em 2005 a empresa Gol apresentou um resultado superior ao da TAM, diferentemente de 2006.

Tabela 6 - Apresentação do score Z" e atribuição de rating em 2006

\begin{tabular}{l|l|l|l|l|l|l|l}
\hline $\begin{array}{l}\text { Coeficiente } \\
\text { Empresas }\end{array}$ & $\begin{array}{l}6,56 \\
\mathbf{X 1}\end{array}$ & $\begin{array}{l}3,26 \\
\mathbf{X 2}\end{array}$ & $\begin{array}{l}6,72 \\
\mathbf{X 3}\end{array}$ & $\begin{array}{l}1,05 \\
\mathbf{X 4}\end{array}$ & $\begin{array}{l}3,25 \\
\mathbf{X 5}\end{array}$ & $\begin{array}{l}\text { Score } \\
\text { Z' }\end{array}$ & $\begin{array}{l}\text { Rating } \\
\text { S\&P }\end{array}$ \\
\hline TAM & 0,2818 & 0,2807 & 0,1989 & 0,4470 & 3,25 & 7,8190 & $\mathrm{AA}+$ \\
Gol & 0,1992 & 0,0906 & 0,3093 & 0,5733 & 3,25 & 7,5323 & $\mathrm{AA}$ \\
Puma & 0,1251 & 0,0680 & 0,1613 & 1,0224 & 3,25 & 6,4497 & $\mathrm{~A}$ \\
Trip & 0,2815 & 0,1762 & $-0,0108$ & 0,4994 & 3,25 & 6,1231 & BBB \\
Abaeté & 0,2659 & $-0,2314$ & 0,0564 & 0,5178 & 3,25 & 5,1629 & BB
\end{tabular}




\begin{tabular}{l|l|l|l|l|l|l|l} 
Absa & 0,1718 & $-0,0300$ & 0,0394 & 0,0088 & 3,25 & 4,5530 & $\mathrm{~B}+$ \\
Total & $-0,2528$ & 0,0155 & 0,1632 & 0,0729 & 3,25 & 2,8150 & $\mathrm{CCC}+$ \\
Pantanal & $-0,1739$ & $-0,0478$ & 0,0458 & 0,2491 & 3,25 & 2,5225 & CCC \\
Mega & $-0,1179$ & $-0,1323$ & 0,0288 & 0,0591 & 3,25 & 2,3007 & CCC- \\
Passaredo & $-0,0682$ & $-0,6556$ & $-0,0354$ & 0,8326 & 3,25 & 1,3015 & D \\
Variglog & $-0,0108$ & $-0,6174$ & $-0,1237$ & $-0,1227$ & 3,25 & 0,2065 & D \\
NHT & 0,3428 & $-0,5571$ & $-0,5965$ & 0,0326 & 3,25 & $-0,2915$ & D \\
Cruiser & $-0,7464$ & $-0,0336$ & $-0,0303$ & 0,0165 & 3,25 & $-1,9424$ & D \\
Oceanair & $-0,1801$ & $-2,6572$ & $-1,2064$ & $-0,1454$ & 3,25 & $-14,853$ & D \\
Webjet & $-0,9362$ & $-1,8250$ & $-1,7603$ & $-0,5412$ & 3,25 & $-21,238$ & D \\
\hline
\end{tabular}

Fonte: Elaborada pelos autores com base nos dados da pesquisa.

Em relação às empresas inoperantes, Cruiser e Variglog apresentaram o rating D. Contrapondo, a Puma alcançou o score 6,4497 , atingindo o rating A, sendo a terceira empresa com o melhor rating de 2006. A alavancagem do score da Puma é justificada pela redução das suas despesas financeiras no período, o que aumentou o lucro do exercício e, consequentemente, o Patrimônio Líquido, influenciando positivamente a variável X4.

Cabe observar a constância do segmento, os resultados se mantiveram, alternando de modo pouco significativo. As demais empresas que integraram a amostra de pesquisa apresentaram scores médios.

Tabela 7 - Apresentação do score Z" e atribuição de rating em 2007

\begin{tabular}{|c|c|c|c|c|c|c|c|}
\hline $\begin{array}{l}\text { Coeficiente } \\
\text { Empresas }\end{array}$ & $\begin{array}{l}6,56 \\
\times 1 \\
\end{array}$ & $\begin{array}{l}3,26 \\
\times 2 \\
\end{array}$ & $\begin{array}{l}6,72 \\
\times 3\end{array}$ & $\begin{array}{l}1,05 \\
\times 4\end{array}$ & $\begin{array}{l}3,25 \\
\times 5 \\
\end{array}$ & $\begin{array}{l}\text { Score } \\
\text { Z" }^{\prime \prime}\end{array}$ & $\begin{array}{l}\text { Rating } \\
\text { S\&P }\end{array}$ \\
\hline Trip & 0,3946 & 0,3918 & 0,0138 & 0,9107 & 3,25 & 8,1648 & AAA \\
\hline TAM & 0,2942 & 0,1360 & 0,1261 & 0,3292 & 3,25 & 6,8161 & $A$ \\
\hline Gol & 0,0591 & 0,0804 & 0,1251 & 0,4323 & 3,25 & 5,1942 & BB \\
\hline Mega & 0,1377 & $-0,1482$ & 0,0263 & 0,2472 & 3,25 & 4,1070 & B- \\
\hline Absa & 0,0164 & $-0,0191$ & 0,0228 & 0,0367 & 3,25 & 3,4867 & $\mathrm{CCC}+$ \\
\hline Total & $-0,1896$ & 0,0133 & 0,1345 & 0,0507 & 3,25 & 3,0068 & $\mathrm{CCC}$ \\
\hline Abaeté & 0,1940 & $-0,4504$ & $-0,1169$ & 0,2899 & 3,25 & 2,5731 & CCC \\
\hline Passaredo & 0,0096 & $-0,5474$ & 0,0098 & 0,4786 & 3,25 & 2,0967 & CCC- \\
\hline Cruiser & $-0,3595$ & $-0,0386$ & 0,0333 & 0,0588 & 3,25 & 1,0515 & $D$ \\
\hline Pantanal & $-0,3311$ & $-0,2480$ & $-0,1168$ & 0,0150 & 3,25 & $-0,4994$ & $D$ \\
\hline Variglog & 0,1546 & $-0,9868$ & $-0,5574$ & $-0,3606$ & 3,25 & $-3,0772$ & $\mathrm{D}$ \\
\hline $\mathrm{NHT}$ & $-0,1238$ & $-1,1412$ & $-0,7639$ & 0,1137 & 3,25 & $-6,2967$ & $\mathrm{D}$ \\
\hline Webjet & $-0,7555$ & $-0,7376$ & $-0,5220$ & $-0,1811$ & 3,25 & $-7,8083$ & $\mathrm{D}$ \\
\hline Oceanair & $-0,1461$ & $-2,0603$ & $-0,8994$ & 0,0363 & 3,25 & $-10,431$ & $\mathrm{D}$ \\
\hline Puma & $-1,0306$ & $-3,1809$ & $-0,2374$ & $-0,6463$ & 3,25 & $-16,154$ & $D$ \\
\hline
\end{tabular}

Fonte: Elaborada pelos autores com base nos dados da pesquisa.

Conforme as informações contidas na Tabela 7, observou-se que, em 2007, a empresa Trip passou a integrar o grupo de entidades com os melhores ratings, alcançando um rating AAA. Foi possível identificar que o Ativo da empresa aumentou significativamente com a aquisição da Azul Linhas Aéreas, trazendo como consequência um rating superior em relação aos outros anos (ANAC, 2007). As empresas Gol e TAM alcançaram um rating A e BB respectivamente. 
As entidades inoperantes alcançaram o rating $D$, sendo assim, elas permaneceram no mesmo patamar dos anos anteriores. Até 2006, as empresas Variglog, Cruiser e Puma atingiram scores que refletem o cenário de possível descontinuação.

Nesse momento, pode-se perceber que, desde o início da análise, os scores das empresas inoperantes estão diminuindo. A variável que influencia fortemente essa diminuição é a X2. A referida variável evidencia a representatividade dos lucros acumulados sobre o ativo total, sendo assim, é capaz de identificar o retorno acumulado em relação ao montante do ativo da empresa. Dentro desse contexto, cabe ressaltar que as empresas inoperantes (Variglog, Cruiser e Puma) possuem em comum prejuízos acumulados de anos anteriores, sendo maior até mesmo que seus próprios ativos. Portanto, o resultado dessa variável é negativo e, ainda, distante de zero, o que impulsiona para baixo os scores atingidos.

Tabela 8 - Apresentação do score Z" e atribuição de rating em 2008

\begin{tabular}{|c|c|c|c|c|c|c|c|}
\hline $\begin{array}{l}\text { Coeficiente } \\
\text { Empresas }\end{array}$ & $\begin{array}{l}6,56 \\
\times 1\end{array}$ & $\begin{array}{l}3,26 \\
\times 2\end{array}$ & $\begin{array}{l}6,72 \\
\times 3\end{array}$ & $\begin{array}{l}1,05 \\
\times 4\end{array}$ & $\begin{array}{l}3,25 \\
\times 5\end{array}$ & $\begin{array}{l}\text { Score } \\
Z^{\prime \prime}\end{array}$ & $\begin{array}{l}\text { Rating } \\
\text { S\&P }\end{array}$ \\
\hline Absa & 0,0200 & 0,0043 & 0,0313 & 0,0492 & 3,25 & 3,6571 & $\mathrm{CCC}+$ \\
\hline Trip & 0,0340 & $-0,0587$ & $-0,0041$ & 0,1405 & 3,25 & 3,4016 & $\mathrm{CCC}+$ \\
\hline TAM & $-0,0546$ & $-0,0124$ & 0,0553 & 0,0496 & 3,25 & 3,2755 & $\mathrm{CCC}+$ \\
\hline Total & $-0,1427$ & 0,0253 & 0,0660 & 0,0618 & 3,25 & 2,9050 & CCC \\
\hline Abaeté & 0,1171 & $-0,5222$ & $-0,0250$ & 0,1750 & 3,25 & 2,3315 & CCC- \\
\hline Passaredo & $-0,0798$ & $-0,3753$ & $-0,0375$ & 0,1805 & 3,25 & 1,4401 & $\mathrm{D}$ \\
\hline Gol & $-0,0652$ & $-0,2244$ & $-0,2558$ & 0,3166 & 3,25 & 0,7040 & $D$ \\
\hline Mega & 0,0321 & $-0,8006$ & $-0,0656$ & 0,0163 & 3,25 & 0,4271 & D \\
\hline Webjet & $-0,1870$ & $-0,1738$ & $-0,3166$ & 0,1953 & 3,25 & $-0,4658$ & $D$ \\
\hline Variglog & $-0,2549$ & $-0,4016$ & $-0,1680$ & 0,0328 & 3,25 & $-0,8264$ & $D$ \\
\hline NHT & $-0,0193$ & $-1,0299$ & $-0,2477$ & 0,2388 & 3,25 & $-1,6480$ & D \\
\hline Pantanal & $-0,5495$ & $-0,5524$ & $-0,1802$ & $-0,2132$ & 3,25 & $-3,5901$ & $D$ \\
\hline Cruiser & $-1,0113$ & $-0,4074$ & $-0,1692$ & $-0,2324$ & 3,25 & $-6,0933$ & D \\
\hline Oceanair & $-0,1116$ & $-1,7413$ & $-1,2678$ & 0,0970 & 3,25 & $-11,576$ & $D$ \\
\hline Puma & $-1,7755$ & $-4,2421$ & $-0,4597$ & $-0,7351$ & 3,25 & $-26,087$ & $D$ \\
\hline
\end{tabular}

Fonte: Elaborada pelos autores com base nos dados da pesquisa.

No exercício de 2008, as empresas do segmento aeroviário apresentaram resultados inferiores aos demais exercícios, conforme pode ser constatado na Tabela 8 . O melhor rating alcançado em 2008 foi CCC+, sendo atingido pelas empresas Absa, Trip e TAM. Deve ser destacado que o resultado alcançado por essas empresas não foi satisfatório, se comparado com os anos anteriores. Conforme interpretação da agência Standard Poor's (2003), o rating CCC+ é caracterizado pela vulnerabilidade corrente à inadimplência, ou seja, as entidades que o atinge tendem a descumprir as obrigatoriedades fixadas com terceiros.

Com base nos resultados alcançados com a aplicação do Z" score de Altman (2002), afirma-se que as empresas do segmento aeroviário brasileiro apresentaram resultados abaixo da média em 2008, se comparados com os resultados dos anos anteriores. Contudo, o ano analisado foi atípico, devido à crise econômica de 2008, que afetou o mercado financeiro diretamente e, de forma indireta, o mercado aeroviário (ANAC, 2008). 
Tabela 9 - Apresentação do score Z" e atribuição de rating em 2009

\begin{tabular}{l|l|l|l|l|l|l|l}
\hline Coeficiente & $\begin{array}{l}\mathbf{6 , 5 6} \\
\mathbf{X 1}\end{array}$ & $\begin{array}{l}\mathbf{3 , 2 6} \\
\mathbf{X 2}\end{array}$ & $\begin{array}{l}\mathbf{6 , 7 2} \\
\mathbf{X 3}\end{array}$ & $\begin{array}{l}\mathbf{1 , 0 5} \\
\mathbf{X 4}\end{array}$ & $\begin{array}{l}\mathbf{3 , 2 5} \\
\mathbf{X 5}\end{array}$ & $\begin{array}{l}\text { Score } \\
\text { Z'" }\end{array}$ & $\begin{array}{l}\text { Rating } \\
\text { S\&P }\end{array}$ \\
\hline Mega & 0,7810 & 1,4686 & 0,0368 & 0,0000 & 3,25 & 13,4084 & AAA \\
Abaeté & 0,4033 & $-0,1794$ & 0,3433 & 0,7199 & 3,25 & 8,3735 & AAA \\
Gol & 0,0279 & 0,0490 & 0,0540 & 0,5794 & 3,25 & 4,5637 & B+ \\
Total & $-0,1317$ & 0,1850 & 0,0311 & 0,2794 & 3,25 & 3,4920 & CCC+ \\
Trip & $-0,0644$ & 0,0425 & 0,0200 & 0,1784 & 3,25 & 3,2878 & CCC+ \\
TAM & $-0,0911$ & 0,0751 & 0,0318 & 0,1623 & 3,25 & 3,2812 & CCC+ \\
Cruiser & $-0,0010$ & $-0,0004$ & $-0,0254$ & $-0,2325$ & 3,25 & 2,8273 & CCC \\
Absa & $-0,0544$ & $-0,0215$ & $-0,1224$ & 0,0254 & 3,25 & 2,0265 & CCC- \\
Passaredo & $-0,2479$ & $-0,2847$ & 0,0588 & 0,2443 & 3,25 & 1,3474 & D \\
NHT & 0,0018 & $-0,9639$ & $-0,1349$ & 0,0053 & 3,25 & $-0,7813$ & D \\
Variglog & $-0,3601$ & $-0,3625$ & $-0,1759$ & 0,0824 & 3,25 & $-1,3894$ & D \\
Webjet & $-0,4355$ & $-0,6950$ & $-0,2823$ & $-0,2894$ & 3,25 & $-4,0733$ & D \\
Puma & $-1,6475$ & $-3,9867$ & 0,8070 & $-0,6700$ & 3,25 & $-15,834$ & D \\
Oceanair & $-0,3313$ & $-4,8130$ & $-0,5514$ & 0,0103 & 3,25 & $-18,308$ & D \\
Pantanal & $-1,0551$ & $-3,0834$ & $-1,8791$ & $-0,7141$ & 3,25 & $-27,100$ & D \\
\hline
\end{tabular}

Fonte: Elaborada pelos autores com base nos dados da pesquisa.

As informações contidas na Tabela 9 permitem inferir que, em 2009, as empresas analisadas também apresentaram scores abaixo da média, se comparadas com 2005, 2006 e 2007 . No entanto, os resultados em 2009 foram superiores aos de 2008. As entidades inoperantes atualmente (Variglog, Puma e Cruiser) permaneceram entre as entidades que auferiram os piores scores. Nesse sentido, pode-se afirmar que, no ano de 2009, elas alcançaram resultados do mesmo nível que nos anos anteriores, ou seja, essas entidades continuaram a auferir prejuízos, o que influenciou negativamente as variáveis $\mathrm{X} 2$ e $\mathrm{X} 4$ e, consequentemente, os respectivos scores.

Cabe ressaltar que as variáveis X2 e X4 são influenciadas fortemente pelo resultado alcançado pela entidade. Ou seja, na variável X2 o lucro ou o prejuízo integra diretamente o cálculo do coeficiente e, em relação à variável X4, o resultado (lucro ou prejuízo) influencia indiretamente, pois o resultado do período é contabilmente incorporado ao Patrimônio Líquido.

Tabela 10 - Apresentação do score Z" e atribuição de rating em 2010

\begin{tabular}{l|l|l|l|l|l|l|l}
\hline \begin{tabular}{l|l} 
Coeficiente \\
Empresas
\end{tabular} & $\begin{array}{l}\mathbf{6 , 5 6} \\
\mathbf{X 1}\end{array}$ & $\begin{array}{l}\mathbf{3 , 2 6} \\
\mathbf{X 2}\end{array}$ & $\begin{array}{l}\mathbf{6 , 7 2} \\
\mathbf{X 3}\end{array}$ & $\begin{array}{l}\mathbf{1 , 0 5} \\
\mathbf{X 4}\end{array}$ & $\begin{array}{l}\mathbf{3 , 2 5} \\
\mathbf{X 5}\end{array}$ & $\begin{array}{l}\text { Score } \\
\mathbf{Z} \text { ' }\end{array}$ & $\begin{array}{l}\text { Rating } \\
\text { S\&P }\end{array}$ \\
\hline Abaeté & 0,4804 & $-0,0190$ & 0,1591 & 0,9744 & 3,25 & 8,4314 & AAA \\
Absa & 0,4439 & $-0,0003$ & $-0,0035$ & 0,0496 & 3,25 & 6,1897 & BBB \\
Gol & 0,1040 & 0,0525 & 0,0887 & 0,5075 & 3,25 & 5,2322 & BB+ \\
Total & $-0,0862$ & 0,1577 & 0,1255 & 0,2691 & 3,25 & 4,3249 & B \\
Trip & $-0,0068$ & 0,0765 & 0,0718 & 0,2113 & 3,25 & 4,1591 & B \\
TAM & $-0,1140$ & 0,0912 & 0,0659 & 0,1795 & 3,25 & 3,4307 & CCC+ \\
Mega & $-0,1070$ & $-0,3617$ & 0,1858 & 0,2493 & 3,25 & 2,8794 & CCC \\
Webjet & $-0,0379$ & $-0,3910$ & 0,0993 & 0,0320 & 3,25 & 2,4275 & CCC- \\
Passaredo & $-0,1977$ & $-0,0844$ & $-0,0308$ & 0,1197 & 3,25 & 1,5959 & D \\
Variglog & $-0,4981$ & $-0,5286$ & $-0,0995$ & $-0,0585$ & 3,25 & $-2,4711$ & D \\
Pantanal & $-0,1373$ & $-1,7496$ & 0,0632 & $-0,5851$ & 3,25 & $-3,5442$ & D
\end{tabular}




\begin{tabular}{l|l|l|l|l|l|l|l} 
NHT & $-0,0152$ & $-2,6897$ & $-0,4938$ & 0,4542 & 3,25 & $-8,4595$ & D \\
Oceanair & $-0,3273$ & $-2,7852$ & $-0,2214$ & $-0,1986$ & 3,25 & $-9,6734$ & D \\
Cruiser & $-1,2303$ & $-1,3093$ & $-0,1341$ & $-0,5338$ & 3,25 & $-10,550$ & D \\
Puma & $-2,5615$ & $-5,8921$ & 1,6128 & $-0,8102$ & 3,25 & $-22,774$ & D \\
\hline
\end{tabular}

Fonte: Elaborada pelos autores com base nos dados da pesquisa.

No último período selecionado para análise, os resultados não foram diferentes. Conforme pode ser constatado a partir das informações resumidas na Tabela 10, em 2010, as empresas que estão inoperantes atualmente (Variglog, Cruiser e Puma) se mantiveram e alcançaram o rating D.

Considerando a finalidade pela qual o modelo $Z^{\prime \prime}$ score de Altman (2002) foi concebido, pode-se afirmar que ele se mostrou eficaz também no ano de 2010, sendo possível afirmar também que, nos anos analisados anteriormente, as entidades Variglog, Cruiser e Puma apresentaram resultados que serviram de base para prever uma possível descontinuidade das suas atividades operacionais. As empresas inoperantes analisadas se descontinuaram efetivamente no ano de 2011 , a pesquisa abordou os cinco últimos anos anteriores, para assim, verificar a eficácia o modelo $Z^{\prime \prime}$.

\section{CONSIDERAÇÕES FINAIS}

A partir da aplicação do modelo Z" de Altman (2002), é possível dimensionar a capacidade financeira de determinada entidade. Dentro desse contexto, pode-se afirmar que a sua produz em informações importantes para tomada de decisão.

De acordo com o modelo desenvolvido por Altman (2002), o Z" score possui a característica de mensurar a capacidade financeira da empresa, portanto, os scores atingidos indicam fortemente se as entidades descontinuarão ou não suas atividades. Dessa forma, pode-se afirmar que, mediante os scores alcançados pelas empresas analisadas nessa investigação, foi possível avaliar a sua viabilidade financeira das empresas e os possíveis riscos de descontinuidade.

Mediante a aplicação do modelo $Z^{\prime \prime}$ de Altman (2002), foi possível determinar a capacidade financeira das empresas do segmento aeroviário brasileiro. Sendo que, nesse sentido, as empresas inoperantes atualmente, Variglog, Puma e Cruiser, apresentaram scores que, reportados à matriz de ratings utilizada nessa investigação, indicaram uma possível descontinuidade das suas atividades para os anos subsequentes aos analisados.

Essas evidências não puderam ser corroboradas por nenhum dos estudos anteriores analisados nessa investigação, pois ora a maioria daqueles estudos concentrou-se nas duas maiores empresas do segmento, ou seja, TAM e Gol (ARANHA; LINS FILHO, 2005; ANTUNES; ALVES; ANTUNES, 2007; NASCIMENTO; PEREIRA; HOELTGEBAUM, 2010), VILLA; ESPEJO, 2011), ora compararam aquelas duas empresas com empresas que descontinuaram suas atividades e, por isso, não integraram a amostra dessa pesquisa (ARANHA; LINS FILHO, 2005; ANTUNES; ALVES; ANTUNES, 2007; OLIVEIRA; SCARPEL; OLIVEIRA, 2008).

Por outro lado, destacou-se a viabilidade financeira das empresas TAM, Gol e Trip. Ambas apresentaram, no decorrer dos anos analisados, scores que reportaram a ratings que indicaram desempenho positivo em termos financeiros.

As evidências relativas à TAM e à Gol foram corroboradas pelos resultados do estudo de Villa e Espejo (2011) que, mesmo utilizando uma modelagem analítica diferente daquela utilizada nesta investigação, sinalizaram uma situação financeira confortável de ambas e, ainda, a recuperação dos respectivos resultados já em 2009, portanto, logo após a crise de 2008.

Em consonância com as interpretações fornecidas pela matriz Standard \& Porr's (2003), observou-se que $60 \%$ (sessenta por cento) das empresas do segmento aeroviário alcançaram, no período analisado, em média, o rating $\mathrm{CCC}+$, sendo assim, essas entidades estão vulneráveis aos riscos de inadimplência. 
De modo específico, devem ser observadas algumas entidades pertencentes a esse grupo, sendo elas, Abaeté, Mega, Oceanair, Passaredo e Pantanal, pois, nos períodos iniciais das análises (2005, 2006 e 2007), elas atingiram ratings que indicaram viabilidade financeira, entretanto, após a crise financeira de 2008, alcançaram resultados insatisfatórios. Tais evidências permitem afirmar que as considerações feitas por Villa e Espejo (2011), acerca da busca por mecanismos de proteção contra possíveis crises econômicas externas, aplicam-se não somente à TAM e à Gol, mas, também, àquelas empresas menores.

Com relação específica ao ano de 2008, quando o melhor rating alcançado foi CCC+, deve-se observar que tal evidência vai contra o que foi constatado por Oliveira, Scarpel e Oliveira (2008). Ou seja, aqueles pesquisadores observaram que a situação econômica doméstica é mais impactante na situação econômico-financeira das empresas do segmento aeroviário brasileiro do que as oscilações cambiais em si. Contudo, os resultados da presente investigação sinalizaram que as variáveis externas relacionadas à crise econômica mundial de 2008 influenciaram significativamente, de forma negativa, os resultados econômico-financeiros de todas as empresas aéreas analisadas nessa investigação.

A pesquisa apresentou limitações que merecem ser destacadas. A primeira delas leva em conta que as empresas do segmento analisado não publicaram seus demonstrativos financeiros de acordo com as normas internacionais de contabilidade. Isso, de certa forma, dificultou a análise comparativa entre as empresas. Destaca-se, ainda, em termos de limitações, que essa investigação é caracterizada por ser um estudo de caso múltiplo, portanto a eficácia do modelo Z" de Altman (2002) refere-se, especificamente, às empresas e aos períodos contemplados na amostra de pesquisa.

A despeito daquelas limitações, a presente pesquisa ratificou a eficácia do modelo $Z$ " de Altman (2002). Nesse sentido, faz-se interessante ressaltar as contribuições desse estudo de caso para a consolidação teórica e utilização empírica do modelo Z" score de Altman.

Adicionalmente, destaca-se que o presente estudo abordou um importante segmento econômico nacional e, dessa forma, pode ser vislumbrada outra contribuição positiva dessa pesquisa, pois apresentou interpretações fáticas relacionadas à capacidade financeira das empresas que integram o segmento aeroviário brasileiro.

De forma a prosseguir com o estudo da técnica de análise discriminante múltipla desenvolvida por Altman (2002), sugere-se a continuidade desse estudo. Para tanto, seria interessante estender o período analisado para, assim, verificar se as empresas que apresentaram rating não satisfatório nos anos de 2009 e 2010 permaneceram com os mesmos resultados nos próximos anos. Essa abordagem de pesquisa não foi realizada no presente estudo, pois, até o momento da sua conclusão, os demonstrativos financeiros auditados das empresas analisadas não estavam disponíveis, em sua totalidade, no ambiente virtual da Agência Nacional de Aviação Civil (ANAC). Estendendo esse estudo conforme sugerido, espera-se que os resultados provenientes dessa pesquisa possam somar-se aos resultados de outras investigações científicas e, assim, contribuir para o debate relacionado à análise discriminante por meio da modelagem proposta por Altman (2002), entre outros pesquisadores dessa temática.

\section{REFERÊNCIAS}

ALTMAN, E. I. Financial Ratios, Discriminant Analysis and Fite Prediction of Corporate Bankruptcy. Journal of Finance, New York, v. 23, n.4. p.589-609, set. 1968.

The Use of Credit Scoring Models and the Importance of a Credit Culture, v.78. New York: Stern School of Business, 2004.

Revisiting Credit Scoring Models in a Basel 2 Evironment. In: ONG, M. Credit Rating: Methodologies, Rationale and Default Risk. London: London Risk Books, 2002.

ALTMAN, E. I; BAIDYA, T. K. N; DIAS, L. M. R. Assessing Potential Financial Problems for Firms in Brazil. Journal of International Business Studies, Basingstoke, v.10, n.2, p.9-24, dez.1979.

ANAC - Agência Nacional de Aviação Civil. Anuário do Transporte Aéreo 2010. Brasília: ANAC, 2010. Disponível em: http://www2.anac.gov.br/estatistica/anuarios.asp. Acesso em: 04 jul. 2012. 
. Anuário do Transporte Aéreo 2011. Brasília: ANAC, 2011. Disponível em: http://www2.anac. gov.br/estatistica/anuarios.asp. Acesso em: 14 jun. 2013.

ANTUNES, J.; ALVES, V. de P. R.; ANTUNES, G. M. B.. Análise das Demonstrações Contábeis das Companhias Aéreas Brasileiras: Fracassos e Sucessos Anunciados? In: Seminário de Administração, 10., 2007, São Paulo. Anais... São Paulo: FEA-USP, 2007. CD-ROM.

ARANHA, J. A. M.; LINS FILHO, O. da S.. Modelos de previsão de insolvências: o termômetro de Kanitz na avaliação de empresas do setor de aviação comercial. In: Jornada Científica do Centro-Oeste de Economia e Administração, 5., 2005, Campo Grande. Anais... Campo Grande: UFMS, 2005.

BNDES - Banco Nacional de Desenvolvimento Econômico e Social. Estudos e pesquisas para avaliação da situação atual e proposição de políticas públicas para o setor de transporte aéreo no Brasil. Brasília: BNDES, 2012. Disponível em: http://www.bndes.gov.br/SiteBNDES/bndes/bndes_pt/ Institucional/Apoio_Financeiro/Apoio_a_estudos_e_pesquisas/BNDES_FEP/prospeccao/chamada_aereo. html. Acesso em: 04 jul. 2012.

BOUROCHE, M; SAPORTA, G. Análise de dados. Rio de Janeiro: Zahar, 1980.

ELIZABETSKY, R. Um modelo matemático para a decisão do banco comercial. São Paulo: Atlas, 1976.

KANITZ, S. C. Como prever falências. Revista Exame, São Paulo, v.12, p.95-102, dez. 1974.

MATARAZZO, D. C. Análise financeira de balanços: abordagem básica e gerencial. 7. ed. São Paulo: Atlas, 2007.

MATARAZZO, D. C. Análise financeira de balanços: abordagem básica e gerencial. 3. ed. São Paulo: Atlas, 1998.

MATHIASI HORTA, R. A; BORGES, C. C. H.; CARVALHO, F, A. A.; ALVES, F. J. S.. Previsão de insolvência: uma estratégia da base de dados utilizando variáveis contábeis de empresas brasileiras - SEID. In: CONGRESSO USP DE CONTROLADORIA E CONTABILIDADE, 11., 2011, São Paulo. Anais... São Paulo: USP, 2011. p.11-45.

NASCiMENTO, S. do; PEREIRA, A. M.; HOELTGEBAUM, M.. Aplicação dos Modelos de Previsão de Insolvências nas Grandes Empresas Aéreas Brasileiras. Revista de Contabilidade do Mestrado em Ciências Contábeis da UERJ (online), Rio de Janeiro, v.15, n.1, p.49-p. 51, jan./abril, 2010. Disponível em: http:// www.e-publicacoes.uerj.br/index.php/rcmccuerj/article/view/5507/4003. Acesso em: 13 jun. 2013.

OLIVEIRA, R. F. de; SCARPEL, R. A.; OLIVEIRA, A. V. M.. Insolvência de empresas e crise: um estudo dos determinantes da saída de mercado de companhias aéreas. Revista de Literatura dos Transportes RELIT, v.2, n.2, p.7-23, Jul. 2008. Disponível em: http://www.pesquisaemtransportes.net.br/relit/index. php/relit/article/view/jv2n2p1/34. Acesso em: 13 jun. 2013

SILVA, J. P. Análise financeira das empresas. São Paulo: Atlas, 1997

STANDARD \& POOR'S. Debt Rating Criteria. New York, 1997. Disponível em: http://www.ratings.standardpoor.com/criteria/index.htm. Acesso em: 04 jul. 2012.

STANDARD \& POOR'S. Rating Definitions and Terminology. New York, 2003. Disponível em <www. standardandpoors.com>. Acesso em: 04 jul. 2012.

SANVICENTE, A. Z.; MINARDI, A. M. A. F. Identificação de indicadores Contábeis significativos para previsão de concordata de empresas. 1998. (Relatório de pesquisa). Disponível em: http://www. risktech.br/artigos/artigos técnicos /index.html. Acesso em: 04 jul. 2012.

VILLA, P; ESPEJO, M. TAM e Gol: Casos representativos da aviação brasileira em tempos de crise. Rev. Portuguesa e Brasileira de Gestão [on-line], Lisboa, v.10, n.4, p. 26-37 out. 2011. Disponível em: http://www.scielo.gpeari.mctes.pt/pdf/rpbg/v10n4/v10n4a04.pdf. Acesso em: 13 jun. 2013.

YIN, R. K. Estudo de caso: planejamento e métodos. 3. ed. Porto Alegre: Bookman, 2005. 